\title{
Urbanization: Planting Forests in Pots
}

\author{
Dr. HOSSEIN SADRI * \\ Visiting Scholar, the City College of New York, CUNY \\ Associate Professor, Girne American University \\ E mail: hosadri@gmail.com
}

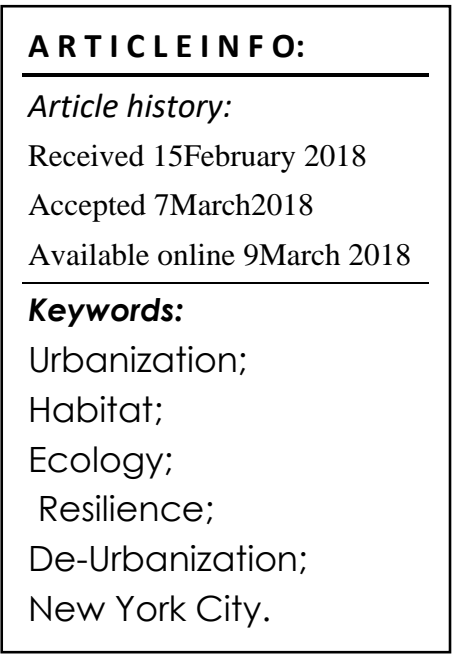

\begin{abstract}
A B S T R A C T
Taking plants from their original habitat and keeping them in pots is an illustrative example of manmade, power-oriented and unnatural habitation. Naturally, a plant cannot survive in a segregated environment of a pot. For this reason, diverse supportive activities such as watering, feeding or protecting must be planned. These supplying infrastructures create a great power for the caretaker over the life of the potted plant. Using the example of potted plants, this article tries to shed light on social and ecological problems of urbanization.
\end{abstract}

JOURNAL OF CONTEMPORARY URBAN AFFAIRS (2018) 2(2), 122-129.

https://doi.org/10.25034/ijcua.2018.4676

This work is licensed under a

Creative Commons Attribution

- NonCommercial - NoDerivs 4.0. "CC-BY-NC-ND"

www.ijcua.com

Copyright (C 2018 Journal Of Contemporary Urban Affairs. All rights reserved.

"To live

like a tree alone and free

and

like a forest in brotherhood"

(Nazim Hikmet Ran, 1940)

\section{Introduction}

Last week Reuters released a news related to the newest study on the wealthiest cities of the world and stated that with 3 trillion dollar wealth, New York City is the richest city of the world (RT, 2018). Forbes reports that New York City is the world capital of ultra-rich people with its 79 billionaires (Savchuk, 2016). These and similar news related to New York City creates an image of a prosperous environment in the mind of readers. However, few minutes of surf in the studies and statistics or a short visit to the city is enough to discover the reverse reality of shortage and poverty in the city. Even though there are many systematic and volunteer social support programs, the pains and distresses of New Yorkers are not relieved. Below I will give examples of these social programs on the issues of homelessness and hunger. In spite of the well-developed and functioning aid programs of public and local authorities, which do not regularly exist in other mega-cities and never exist in smaller towns, the insufficiency of these programs is easily readable from the

\footnotetext{
*Corresponding Author:

Visiting Scholar, The City College of New York, CUNY

Associate Professor, Girne American University, Turkey

E-mail address: hosadri@gmail.com
} 
existing conditions and the growing rates of social problems in the city.

Both the state government in New York and the New York City management have several housing aid programs such as the Homeless Housing and Assistance Program (HHAP), the Solutions to End Homelessness Program (STEHP), New York State Supportive Housing Program (NYSSHP), Housing Opportunities for Persons with AIDS Program (HOPWA), Emergency Needs for the Homeless Program (ENHP), and the Operational Support for AIDS Housing Program (OSAH) administered by the Housing and Support Services (HSS) of New York government and Department of Homeless Services New York City (OTDA, 2018). Nevertheless, during the year 2017 , 130,000 homeless people including 45,000 children slept in the municipal shelter system of New York City (Coalition for the Homeless, 2018). According to the reports of the federal government in the United States, the number of homeless people in New York City is the highest one in the United States (Iverac, 2017).

In addition to the 250 million meals, which are served in schools, or through the non-profit partners in homeless shelters, care centers and public hospitals, New York City also directly distributes 250 million meals every year. The city management establishes food supporting programs such as Emergency Food Assistance Program (EFAP) which serves 5.5 million $\mathrm{Kg}$ of food for 15 million people annually and The Supplemental Nutrition Assistance Program (SNAP) which serves 1.7 million New Yorkers. However, the meal gap in New York City is very high; and 225 million meals are missing from the homes of the families struggling with food insecurity every year. There are almost 1.3 million food-insecure New Yorkers. (NYC Food Policy, 2017). New York City has the highest number of food insecure individuals in the United States (Feeding America, 2017)

\section{Where the Problem Comes From?}

New York City contains almost the same variety of the problems that all other urban areas around the world are facing, with a much more gravity and seriousness. In this sense, New York is a prototypical urban area in which a huge number of people with the variety of problems and opportunities are aggregated (Lindsay, 1974). Supplying the needs of these people is highly dependent on the systematic tools, technological means, resources and energies. Robson declares that without these supports, the survival of these vast aggregations of people in their concentrated urban areas is impossible. He underlines the dependency of urban inhabitants on the machines and mechanisms of transfer, filtration, and administration of drinking water, or the services and systems of waste collection and sewerage (Robson, 1972).

This urban society is the result of industrialization and domination of capitalism and as Lefebvre explains is highly interrelated with the establishment of urban infrastructures (Lefebvre, 2003). These supporting systems and infrastructure are developed to fulfill the missing functions of the human habitat that in any natural habitat originally exists. This artificiality and vulnerability of urban habitat and its dependency on external energies support and care from the outer resources, reminds me the condition of a potted plant.

\section{How Potted Plants Survive?}

Plants originally grow on earth under the conditions deriving from their co-operations and inter-relations with other living beings such as plants, fungi, microbes, insects and animals, in addition to other climatic and physical conditions. These co-operations create some niches such as microclimates supportive to the growth of a specific plant and build a resilient environment for its life. The highest resiliency and sustainability, the best living conditions and overall performances of plants can be found in forests where the most diverse and strong interconnections exist. Conversely, potted plants and their fragile life conditions originate from their complete isolation from the resources of life such as water and food, and their destitution from any solidarity and collaboration. Johns expresses this instability with the mutative health conditions of potted plants changing even between morning 
and evening of the same day from a healthy to a seriously diseased condition (Johns, 1974).

The extremely artificial life of potted plants makes special care necessary (Johns, 1974). Neglecting of this care even for a short while has a fatal effect on their life mainly because of the limited amount of exhausted and dead soil - in a period after planting - separated from natural conditions, resources and organisms (Beckett and et al, 1983, Fogg, 1959, and Johns, 1974). As much as the lifespan of a potted plant is longer, its vulnerability - when potted in a container - is higher and consequently, its need for care is more. Accordingly, seasonal plants require less care than annual and perennial ones (Fogg, 1959).

Today science and technology gives us enough power to build the necessary infrastructure and provide and control the needed artificial conditions for potted plants such as adequate climatic conditions, watering (irrigation) and feeding (fertilization) even with smart tools (Figure 1) - this recalls the idea of smart cities.

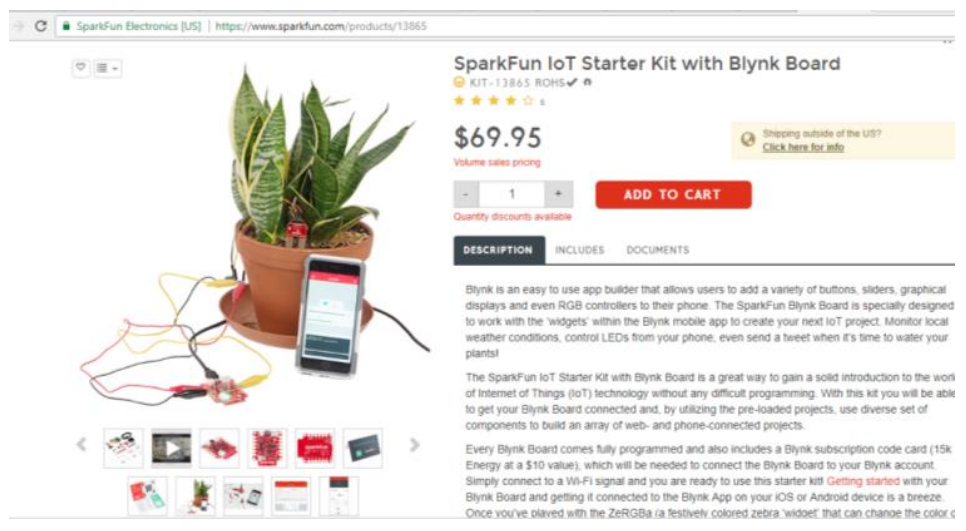

Figure 1. Diverse kinds of smart kits which make the control of the living conditions of potted plants easier (Sparkfun Website)

The variety of chemicals produced and used to create a "protective" environment for the potted plants and support their artificial health such as pesticides and insecticides, fungicides, paints and sealants, anti-desiccants, disinfectants and sterilizers and deterrents (Beckett and et al, 1983). To keep them alive for a long period, it is necessary to keep them in laboratory conditions, and continuously re-pot them (Figure 2).
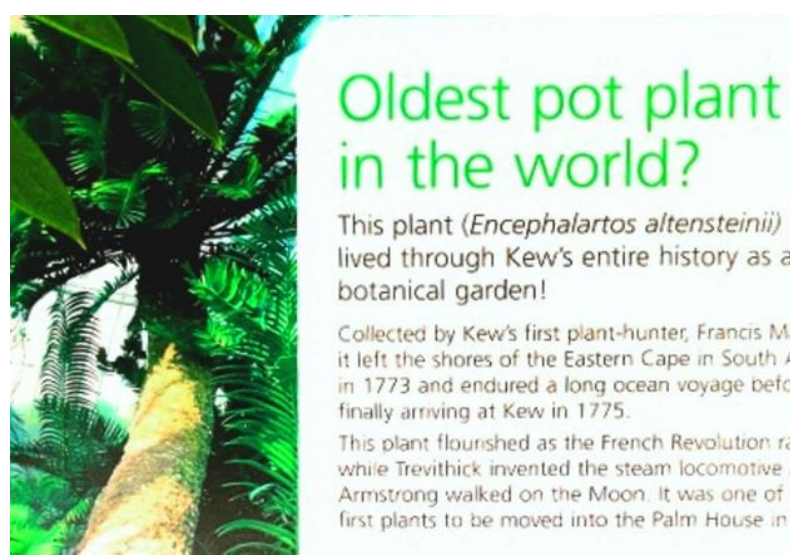

This plant (Encephalartos altensteinii) has lived through Kew's entire history as a botanical garden!

Collected by Kew's first plant-hunter, Francis Masson, it left the shores of the Eastern Cape in South Africa in 1773 and endured a long ocean voyage before finally arrving at Kew in 1775 .

This plant flourshed as the French Revolution raged whie Trevithick invented the steam locomotive and Armistrong walked on the Moon. It was one of the first plants to be moved into the Palm House in 1848

Figure 2. The oldest potted plant in the world is in the "living laboratory" of the Royal Botanical Gardens in Surrey (Kew Website)

However, the majority of the potted plants which do not have the luck of being kept in laboratory conditions or under highly sensitive care circumstances die in the early stages of their life.

On the contrary of the forests which exist to provide life not only to their dwellers but to all beings on the planet, pots and containers foundationally provide death to their plants. In addition to this friable life in pots and containers, while forests do not require any external care, habitation in pots require a huge amount of time and energy to compensate the survival circumstances of their inhabitants -just as the urban areas of today.

\section{What about Forests?}

In 2016, Peter Wohlleben published a book on the secret world of forests entitled "The Hidden Life of Trees: What They Feel, How They Communicate Discoveries from a Secret World". The book describes the fact that forests are not a simple conglomeration of trees, other plants and living beings; they are superorganisms which act as a whole. He refers to the human beings' short lifespan compared to trees - which can live over thousands of years - as the main reason of becoming unfamiliar with the life of trees and highlights that collaborative life of forest, solidarity between trees and sharing of resources in forest are fundamental grounds of this long life (Wohlleben, 2016).

According to Wohlleben, forests contain an 
infrastructure that enables communication and exchange between its inhabitants. Mainly fungal network in the soil which he calls "wood wide web" creates this capability of sharing information and goods. In addition to this network, the interconnected root system of trees in forests is another way of nutrient exchange and support between trees. Wohlleben says that the connected trees have no other choice but to exchange and he refers to the amazing results of a research done by the Institute for Environmental Research at RWTH Aachen which presents the equal growth of trees in a beech forest as a result of their synchronized photosynthesis performance. Trees equalize their differences with the help of connected roots and fungal networks in a way that strong ones support the weaker ones and accordingly, by growing together and in a synchronized way, they can optimize nutrient and water savings and divisions and all of them can reach to the ideal growing of their kind. He expresses that the reason that trees are becoming social beings is the advantage of being together:

"A tree is not a forest. On its own, a tree cannot establish a consistent local climate. It is at the mercy of wind and weather. But together, many trees create an ecosystem that moderates extremes of heat and cold, stores a great deal of water, and generated a great deal of humidity. And in this protected environment trees can live to be very old" (Wohlleben, 2016, p: 4).

According to Wohlleben, the forest loses its unity and consequently its existence when the vulnerable trees disappear. Their vanishing results in the penetration of the hot sun and strong winds into the forest floor, disruption of moist, and accordingly loss of other trees because of the disability of forest to act as a closed unit and to create its own microclimate (Wohlleben, 2016).

\section{Have any Human Habitats Similar to Forests Existed?}

Ralph Becker in his article of "Three Delusional Ideas of the Western World on Natural Environment, Humans, and Their Societies" shares a story:

"An anthropologist proposed a game to the kids in an African tribe. He put a basket full of fruit near a tree and told the kids that whoever got there first won the sweet fruits. When he told them to run they all took each other's' hands and ran together, then sat together enjoying their treats. When he asked them why they had run like that as one could have had all the fruits for himself they said: "UBUNTU! How can one of us be happy if all the other ones are sad?" (Becker, 2015, p: 382).

Becker explains that Ubuntu is the short form of a proverb in South African Xosha culture: "Umuntu ngumuntu ngabantu". This proverb means that the existence of anyone is possible through her relations with others. Accordingly, Ubuntu means, "I am because, we are" (Becker, 2015).

Becker refers to the studies of Dalene Swanson and Martin J. Gannon and expresses that the culture of Ubuntu and what can be called communalism is not particular to South Africa but all parts of Sub-Saharan Africa. This is a culture of interconnection with other members of community even with future generations and strong dependency on land (Becker, 2015).

Similar studies can be found related to the communal life and habitation culture of the Native Americans, Polynesians, Aborigines and many other "non-civilized" societies - with colonial terms.

\section{When Have Urban Societies Been Planted in Pots?}

I believe that "civilized" cities - with their bastions, walls and gates, their concrete insulations from food production and other means of life, their division from other communities, their immortal constructions which were built against nature and still fighting with it - have been structures with an endless need of external support and accordingly fragile habitats similar to pots. Spiro Kostof in his book entitled "The City Shaped: Urban Patterns and Meanings through History" gives a clear hint related to the fundamentality of city - pot relations by expressing the inter-connection of the 
termination of self-sufficient habitats with the foundation of urban settlements:

"Cities started when there was a shift away from a simple, self-satisfying village economy" (kostof, 1991, p: 31)

However, this vulnerability rose to the highest degree during the post-industrial urbanization period, mainly because of being over-populated and over-constructed urbanized clusters encircled by sub-urbanized areas - in contrast with the ancient small towns that were surrounded and supported by rural habitats (Davis, 1965).

\section{What Are the Main Problems of Potted Urban Areas?}

The below graphic (Figure 3) created by Jon Lang expresses the way that functions of the built environment tries to answer human needs.

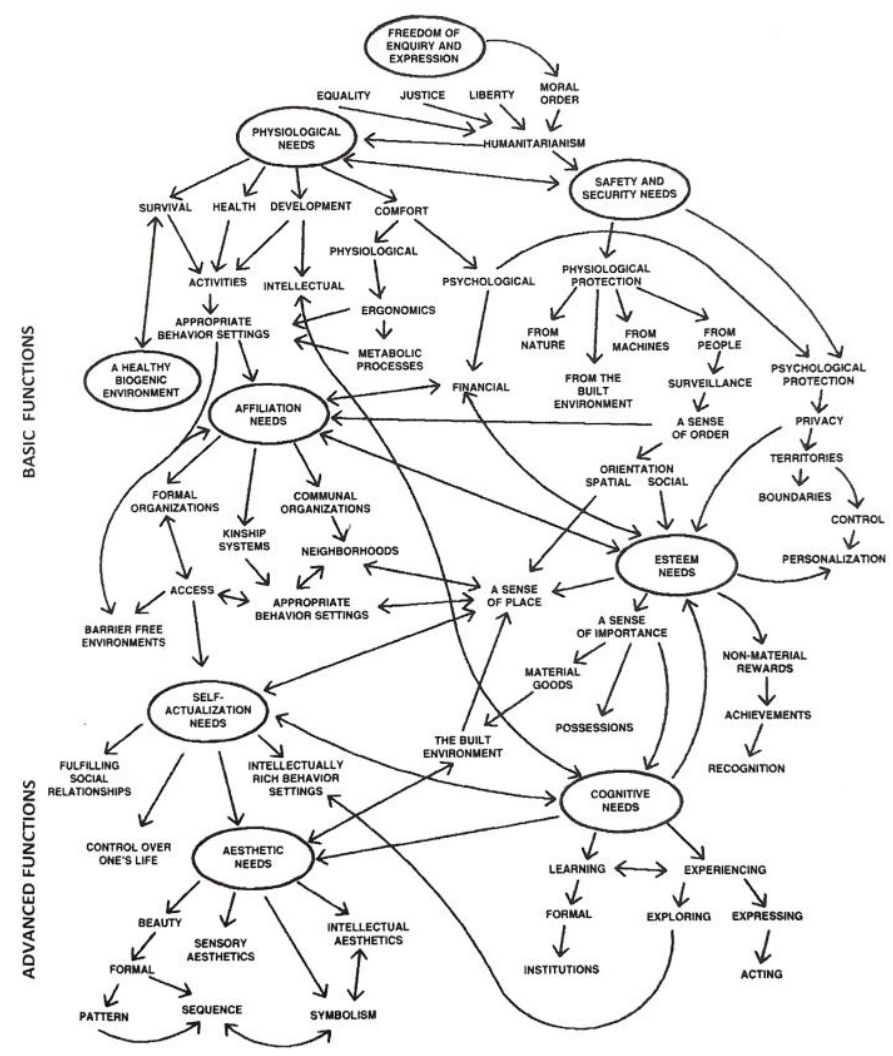

Figure 3. Human needs and the function of the built environment (Lang, 2017, p: 15)

The complex and multi-layered inter-relations presented in the above graphic expresses the similarity of human settlements to forests in terms of diversity and complexity. However, at the same time, it shows the inevitability of grassroots connections and communal collaborative actions which urbanized societies are not set up on these horizontal organizations.

Urbanized societies prefer "well designed" centrally ruled systems. The main aim of these systems, provided by diverse forms of oligarchy including capitalism, is to concentrate the power of control over the resources and their distributions in a centre controlled by the powerful rulers - in other saying caretakers. As a result, the first problem of the potted - centrally administered on-grid over-populated - megaurban areas is the concentration of power in the hand of a small group.

The inhabitants of mega-urban areas do not have access to enough resources for their survival needs. They do not have enough powerful interconnections between each other - or even awareness on this matter - to develop solidarities and co-operations for supplying these needs. The way they are educated and culturally grow makes them completely dependent individuals and does not let them have any skills to establish a more resilient life for themselves. Accordingly, the second problem is the vulnerability of this lifestyle and the urban system. Pots always need caretakers for their watering, feeding, healthcare and other survival needs.

Urban areas are overpopulated areas with the lack of resources and unfair systems of access and control over these resources and accordingly, they are the places of competition for limited resources. Majority of their inhabitants suffer from discrimination, poverty, and injustice and consequently, urban societies face crime, conflict, terror and violence. The third problem of urbanization is the creation of injustice and violence.

"To feed" and "to water" this huge population, to educate, control, and entertain them, summarily to build adequate infrastructure and tools to cover their needs, urbanized areas destroy nature. Accordingly, the fourth complication of 
urbanization is today's crucial problem of environmental and ecological degradation that is the sub-product of urbanized society (Barnett, 1974).

One of the main differences between forests and pots is their lifetime. While forests dominantly contain perennial plants with long lifespans, seasonal and annual plants are preferred in pots. The same problem can be arguedabout the urbanized areas where temporal life is more dominant. Urbanization supports and is supported by high mobility of population. While on one hand migration as a long-term and residence-led mobility creates diversity which gives a high potential and energy of founding a forest-like relations, on the other hand the high percentage and dominance of daily or short-term visits to urban areas on the local inhabitants breaks human-land connections and frustrates permanent and long-term inter-connections and collaborations. Examples from New York City present how temporality of life in urban areas comes true. More than half of Manhattan's daytime population are daily visitors who are not staying in the city during nights (Moss and Qing, 2012). From this daytime population, only $35 \%$ live in their own houses and the other two third are tenants who change their houses frequently (NYC Planning). This kind of temporality makes urban societies without multigenerational perspective and long-term vision, with serious lack of collective memory and sense of belonging, no resiliency and no capability of resistance. The loss of permanent habitation strategies and long-term visions deriving from the temporal residency which is granted by urbanization is the fifth problem of urbanized societies.

Mass population of urbanized areas generates and accumulates a great number of diverse needs that paves the way for the growing of the culture of consumption in a market-oriented capitalist world. Urbanized societies use, manipulate, burn everything including materials, foods, nature and even culture and transform them to waste. Consumption and its sub-products such as waste and pollution can be counted as the sixth problem of urbanization.

\section{Is It Possible to Replant Urban Areas in Forests?} Looking at the below image of a potted city and imagining the replantation of these structures in a forest resembles a violent action similar to agriculturalization of forest lands, or passing huge pipelines from the middle of forests or more similarly dumping construction wastes into forests.

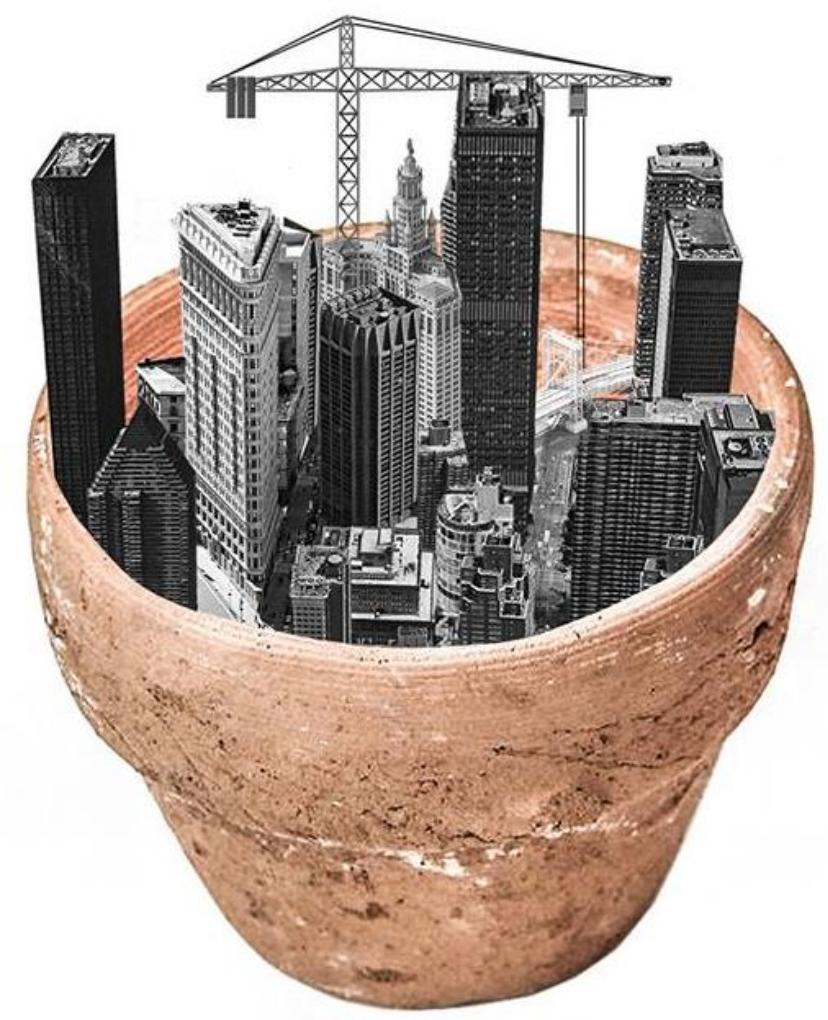

Figure 4. An Urban Area in A Pot, By Serap Sonmez (Sonmez, 2018)

Additionally, replanted urban areas in forests will not act as a part of the forest without a comprehensive restorative action. This follows the same logic of the difference between planted forests and natural forests. Wohlleben describes that planted forests, because of the irreparable damage to their roots, are incapable of communication and networking with other parts of the forest. These plants always behave "like loners and suffer from their isolation" (Wohelleben, 2016, p:5).

Consequently either the damage of the roots must be fixed, prior to the commencement of the integration of urban areas in forests, or reforestation must be started from deserts - or both of these strategies. That is to say, as the first way, 
physical environment must be regenerated in a way that settlements exist in harmony with nature. Additionally, anthropocentric and individualist mind-set of urban societies must be culturally rehabilitated. As the second way, with correct strategies, reforestation of deserts can be realized. In other words, communities outside of the existing system can investigate on the rebuilding of human nature and human-human relations and spread their alternative achievements to the global community. Following any of these ways, the new human habitation model must be as diverse, multilayered and complex as cities, but distinctively with strong relations to its land, permanent and multigenerational strategies, self-sufficient and off-grid settlements in harmony with nature, horizontal organizations, and people with strong loyalty to communal life and solidarity.

The hazardous conditions of global human society and planet today, lead us to try these solutions. Either we will win and natural life will be regenerated or nature will win and will be regenerated - but without us.

\section{Acknowledgments}

This article is developed from the author's lecture entitled "Plants in Pots: Architecture and Power" in the 25th of January of 2017 at Abdullah Gul University in Kayseri, TURKEY. Most of the information during this research accessed from the SSA, CCNY, CUNY library and New York Public Library.

\section{References}

Barnett, J. (1974). Urban Design as Public Policy: Practical Methods for Improving Cities, Architectural Record Books:New York.https://books.google.com.tr/books/about/ Urban_Design_as Public_Policy_Practical.htmlei $d=a 6 k F t A E A C A A J \&$ redir esc $=y$

Becker, R. M. (2015). Three Delusional Ideas of the Western World on Natural Environment, Humans, and Their Societies, Estudos de Sociologia, Recife, 2015, Vol. 2 n. 21.https://www.academia.edu/35836859/Three Delusional Ideas of the Western World on $\mathrm{N}$ atural_Environment_Humans_and_Their_Societie $\underline{s}$

Beckett, K. A., Carr, D. and Stevens, D. (1983) .The Containered Garden, The Viking Press: New York.https://www.amazon.com/Contained-

Garden-Revised-KennethBeckett/dp/0670847291

Coalition for the Homeless. (2018). New York City Homelessness: The Basic Facts, Retrieved on the 1st March 2018 from:

http://www.coalitionforthehomeless.org/wpcontent/uploads/2018/02/NYCHomelessnessFa ctSheet_12-2017_citations.pdf

Davis, K. (1965). The Urbanization of the Human Population in LeGates, R. T. and Stout, F. (1996) The City Reader, Routledge: New York.http://hiebertglobalcenter.org/blog/wpcontent/uploads/2013/04/Reading-7-Davis-TheUrbanization-of-the-Human-Population.pdf

Feeding America. (2017). Map the Meal Gap 2017. The Howard G. Buffett Foundation, Retrieved on the 1st March 2018 from http://www.feedingamerica.org/research/map -the-meal-gap/2015/2015-mapthemealgapexec-summary.pdf

Fogg, W. H. G. (1959). Growing Pot Plants From Seed, Faber and Faber:London.https://www.researchgate.net/p ublication/323701498_Urbanization_Planting_For ests in Pots

Hikmet, N. (1940). retrieved on 26.02.2018 from: http://www.nazimhikmet.org.tr/kronolojik3en.asp

Iverac, M. (2017). More Homeless People Live in New York Than in Any Other City, WNYC News, Dec. 6, 2017, Retrieved on the 1st March 2018 from https://www.wnyc.org/story/morehomeless-people-live-new-york-any-other-city/

Johns, L. (1974). Plants in Tubs, Pots, Boxes and Baskets, Van Nostrand Reinhold, New York.https://www.amazon.com/Plants-TubsPots-Boxes-Baskets/dp/0715363522

Kew Website, Royal Botanical Gardens in Surrey, Retrieved on the 1st March 2018 from: https://www.kew.org/kewgardens/attractions/palm-house

Kostof, S. (1991). The City Shaped: Urban Patterns and Meanings Through History, Bulfinch Press:London.https://thamesandhudson.com/ci 
ty-shaped-urban-patterns-and-meanings-

through-history-9780500280997

Lang, J. (2017). Urban Design: A Typology of Procedures and Products, Routledge:New York.https://www.taylorfrancis.com/books/9781 317282914

Lefebvre, H. (2003). The Urban Revolution, University of Minnesota Press:London.https://thecharnelhouse.org/wpcontent/uploads/2017/08/Henri-Lefebvre-TheUrban-Revolution.pdf

LeGates, R. T. and Stout, F. (1996). The City Reader, Routledge:New

York.https://www.amazon.com/City-ReaderRoutledge-Urban/dp/1138812919

Lindsay, J. V. (1974). Foreword, in Barnett, J, Urban Design as Public Policy: Practical Methods for Improving Cities, Architectural Record Books:New

York.http://usd.tehran.ir/Portals/O/DataBase/Libr ary/Urban\%20Design.pdf

Moss, M. L. and Qing, C. (2012). The Dynamic Population of Manhattan, Rudin Center for Transportation Policy and Management, Wagner School of Public Service:New York University,

New

York.https://wagner.nyu.edu/files/rudincenter/d ynamic_pop_manhattan.pdf

NYC Food Policy. (2017). Food Metrics Report 2017, The City of New York.https://www1.nyc.gov/assets/foodpolicy/d ownloads/pdf/2017-Food-Metrics-ReportCorrected.pdf

NYC Planning, New York City Population, Retrieved on the 1st March 2018 from: https://www1.nyc.gov/site/planning/datamaps/nyc-population/population-facts.page

OTDA. (2018). the Website of the Office of Temporary and Disability Assistance of the New York Government Retrieved on the 1st March 2018 from https://otda.ny.gov/programs/housing/

Robson, W. A. (1972). Great Cities of the World: Their Government, Politics and Planning, George Allen and Unwin LTD:London.https://trove.nla.gov.au/work/1051 5599? q\&versionld $=45247873$

RT. (2018) World's 15 richest cities revealed - and the list contains a few surprises, Reuters, Feb. 25, 2018, Retrieved on the 1st March 2018 from https://www.rt.com/business/419764-worldwealthiest-cities-map-economy/

Savchuk, K. (2016). New York Is The City With The Most Billionaires, Not Beijing, Forbes, March 1, 2016, Retrieved on the 1st March 2018 from https://www.forbes.com/sites/katiasavchuk/201 6/03/01/new-york-mostbillionaires/\#49c8f593489d

Sonmez, S. (2018). An Urban Area in a Pot. Girne American University, Department of Architecture,

Girne.http://ijcua.com/index.php/ijcua/article/ view/52

Sparkfun Website, Retrieved on the 1st March 2018 from

https://www.sparkfun.com/products/13865

Wohlleben, P. (2016). The Hidden Life of Trees: What The Feel, How They Communicate Discoveries from a Secret World, Greystone Books:Vancouver,

Canadahttps://www.amazon.com/Hidden-LifeTrees-Communicate Discoveries-

Secret/dp/1771642483 